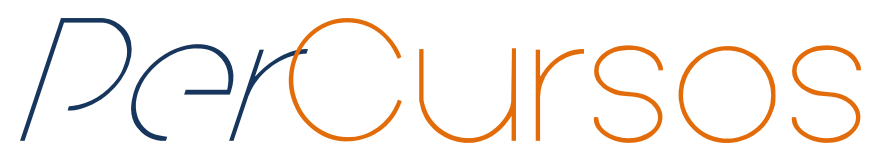

\title{
O ensino médio em disputa: a perspectiva política e ideológica da Folha de S. Paulo
}

\section{Resumo}

Este breve artigo procura analisar a perspectiva política e ideológica do jornal Folha de S. Paulo, especialmente no que se refere a uma das etapas da Educação Básica (Ensino Médio), por meio da parceria do jornal com institutos e grupos ligados a bancos privados, como é o caso do Unibanco. Como desdobramentos destas parcerias, o veículo midiático tem defendido em seus editoriais a meritocracia e o bônus por desempenho docente nos territórios educativos públicos.

Palavras-chave: Folha de S. Paulo. Ensino Médio. Currículo e Avaliação Escolar.

\author{
Jéferson Silveira Dantas \\ Doutor em Educação pela \\ Universidade Federal de Santa \\ Catarina - UFSC. Professor da \\ Universidade Federal de Santa \\ Catarina - UFSC. \\ Brasil \\ jeferson.dantas@ufsc.br
}

Felipe Ferreira da Silva Graduando em Educação Física na Universidade Federal de Santa Catarina.

Brasil

flipeferreiras@gmail.com

\section{Para citar este artigo: \\ DANTAS, Jéferson Silveira; SILVA, Felipe Ferreira da. O ensino médio em disputa: a perspectiva política e ideológica da Folha de S. Paulo. Revista PerCursos, Florianópolis, v. 18, n.36, p. 259 - 276, jan./abr. 2017.}

DOI: $10.5965 / 1984724618362017259$

http://dx.doi.org/10.5965/1984724618362017259 


\title{
The secondary education in dispute: the political and ideological perspective of Folha de S. Paulo
}

\begin{abstract}
This short article aims to analyze the political and ideological perspective of the newspaper Folha de S. Paulo, especially with regard to one of the stages of Basic Education (High School), through newspaper partnership with related institutions and groups to private banks, as is the case of Unibanco. As consequences of these partnerships, the media vehicle has argued in its editorial meritocracy and performance bonuses for teaching in public educational territories.
\end{abstract}

Keywords: Folha de S. Paulo. High School. Curriculum and School Evaluation. 


\section{Considerações Iniciais}

Recentemente, o jornal Folha de S. Paulo publicou um caderno especial referente à gestão escolar, tendo como título O nó do Ensino Médio: como melhorar a educação pública no país, datado de 5 de setembro de 2015. De acordo com a chamada de capa do caderno especial, o Ensino Médio seria a única etapa da Educação Básica que não teria avançado em termos de qualidade desde a década passada, posicionando o Brasil entre os piores nos 'rankings mundiais'. Nem mesmo os alunos 'mais ricos' conseguem ter desempenho satisfatório nesta etapa da Educação Básica, o que ainda é pior para a juventude que está na rede pública, já que esta última concentra $87 \%$ das matrículas em números absolutos, segundo argumentação do periódico (NÓ, 2015, p. 1).

A saída estaria na 'gestão', conforme deliberado no Seminário Internacional Caminhos para a qualidade da educação pública: gestão escolar, realizado pela Folha de S. Paulo e pelo Instituto Unibanco, nos dias 2 e 3 de setembro de 2015, na cidade de São Paulo. Ficam explicitadas e/ou evidenciadas desde já as perspectivas deste grupo midiático no que se refere ao modelo de gestão ideal para a educação pública, qual seja, aquela representada pelas parcerias entre o público e o privado. Em outras palavras, boas experiências educativas nos melhores sistemas educacionais do mundo não estariam diretamente relacionadas à alocação de recursos, mas à 'mobilização da comunidade'. Há, portanto, exemplos provenientes do Canadá e Austrália, que teriam aprimorado a cooperação entre governo, diretores de escola, professores e sindicatos, assim como uma longa discussão referente ao currículo para a Educação Básica. No que tange ao Brasil, a Folha de S. Paulo compreende que a definição da Base Nacional Comum Curricular (BNCC) seria um fator preponderante para "resgatar o Ensino Médio do marasmo" (NÓ, 2015, p. 1).

Além disso, a Folha de S. Paulo aponta os principais problemas relacionados à baixa qualidade no Ensino Médio, a partir da consulta a 'especialistas', por meio de seis pontos: 1) Currículo; 2) Estudantes com baixo desempenho desde o Ensino Fundamental; 3) Falta de perspectiva com o Ensino Médio; 4) Formação dos professores; 5) Falta de democracia nas escolas; 6) Má gestão e insuficiência de recursos. Os especialistas ouvidos foram os 
seguintes: a) Bárbara Melo, presidente da UBES (União Brasileira dos Estudantes Secundaristas); b) Daniel Cara, coordenador-geral da Campanha Nacional pelo Direito à Educação; c) Herman Voorwald, secretário estadual de Educação de São Paulo'; d) Ocemar Alavarse, professor da Faculdade de Educação da USP; e) Priscila Cruz, diretora da ONG “Todos pela Educação"; f) Rafael Lucchesi, diretor da CNI (Confederação Nacional da Indústria) g) Ricardo Henriques, superintendente-executivo do Instituto Unibanco; h) Roberto Leão, presidente da CNTE (Confederação Nacional dos Trabalhadores da Educação); i) Rossieli da Silva, vice-presidente do CONSED (Conselho de Secretários Estaduais de Educação); j) Solon Caldas, diretor da ABMES (Associação Brasileira de Mantenedoras do Ensino Superior); k) Sylvia Gouvea, membro do Conselho Estadual de Educação de São Paulo e I) Wagner Santos, coordenador do programa “Jovens urbanos". Em nota de rodapé, o caderno especial da Folha de S. Paulo ainda traz pequenos depoimentos de Julio Cesar da Costa Alexandre, secretário municipal de Educação de Sobral/CE; Maurício Holanda Maia, secretário de Estado de Educação do Ceará; Anthony Mcnamara, associado internacional do National College for Teaching and Leadership no Reino Unido; Ricardo Paes de Barros, economista e professor do Insper; Francisco Soares ${ }^{2}$, presidente do INEP (Instituto Nacional de Estudos e Pesquisas Educacionais Anísio Teixeira); Vinicius Mota, secretário de Redação da Folha de S. Paulo; Ricardo Madeira, professor de economia da USP; Raquel Teixeira, secretária de Estado de Educação de Goiás; Michael Wilshaw, chefe de inspeções do Ofsted (Escritório de Padrões em Educação) da Inglaterra; Lucia Couto, gerente de desenvolvimento e conteúdos do Instituto Unibanco; Renato Janine Ribeiro, então ministro da Educação ${ }^{3}$; Claudia Costin, diretora sênior para Educação do Banco Mundial; Manuel Palacios, secretário de Educação Básica do MEC; Ana Estela de Sousa Pinto, editora de Mercado da Folha de S. Paulo; Pedro Malan, ex-ministro da Fazenda do governo FHC e vice-presidente do Conselho do Instituto Unibanco; Mirela de Carvalho, gerente de Gestão do Conhecimento

\footnotetext{
${ }^{1}$ Foi exonerado devido ao desgaste referente à ocupação das escolas pelos jovens do Ensino Médio em vários bairros da cidade de São Paulo, resultado de uma inepta política pública de reorientação curricular da Educação Básica, sobretudo, do Ensino Médio.

2 Também exonerado durante a elaboração deste artigo.

${ }^{3}$ Renato Janine Ribeiro foi substituído na pasta do Ministério da Educação por Aloizio Mercadante, que estava na chefia da Casa Civil, na reforma ministerial do governo Dilma Rousseff.
} 
do Instituto Unibanco e Sérgio Roberto Gomes, diretor de valorização dos profissionais da educação da Secretaria de Articulação com os sistemas de ensino do MEC.

Assim, o jornal Folha de S. Paulo, nesta matéria especial dedicada ao Ensino Médio insiste em trazer exemplos externos para demonstrar, de acordo com a sua perspectiva, o quanto as iniciativas de países como o Canadá e a Austrália podem ser utilizadas para discutirmos a Base Nacional Comum Curricular. Para tanto, a questão da 'gestão escolar' é central, o que fez com que o MEC desenvolvesse programas de qualificação e certificação dos diretores das escolas de Educação Básica de todo o país. A lógica defendida por este grupo midiático é aquela relacionada ao bônus de desempenho docente (accountability) e à prática meritocrática nos territórios educativos. Para Ferreira (2015), contudo, faz-se desnecessária a construção e a aprovação de uma Base Nacional Comum Curricular, tendo em vista que desde a década de 1980 os entes federativos têm desenvolvido propostas curriculares regionais mais assentadas às peculiaridades e/ou diversidades de um território tão vasto como é o caso do Brasil.

Cabe enfatizar também que determinadas terminologias utilizadas, ainda que indiretas ou implícitas, pelos especialistas que elaboraram a BNCC e, de certa forma, em consonância com o que pensa o grupo midiático do qual faz parte a Folha de S. Paulo, retoma preceitos do período da ditadura civil-militar (1964-1985) em nosso país, ou seja, os professores precisam ser 'treinados' ou 'adestrados', como queriam os militares (DANTAS, 2009; 2014) e não 'formados', como defendemos. A ideia de 'treinamento' docente sugere em sua acepção uma compreensão tecnicista e pragmática do conhecimento, ou em outras palavras, a execução de atividades pedagógicas que necessitam atender às avaliações em larga escala, ainda que isto signifique a não apropriação do conhecimento propriamente dito (FERNANDES, 2015). Tais avaliações em larga escola (SAEB, ENEM, PROVINHA BRASIL), transplantadas da experiência curricular estadunidense já deram demonstrações de seu retumbante fracasso (GERALDI, 2015), justamente no momento histórico em que a LDBEN 9.394/1996 completa 20 anos de existência.

São notórias, destarte, as conexões deste grupo midiático com determinadas perspectivas educacionais, alicerçadas no modelo privado, tendo como interlocutores 
economistas, ONGs e os Organismos Multilaterais (OM), dentre eles o Banco Mundial. Segundo Gilberto Nogara Junior (2015, p. 38-39)

[...], é importante observar como o Estado, por meio das políticas educacionais, ao privilegiar determinados programas para determinados níveis de ensino, age em consonância aos preceitos pré-estabelecidos no campo econômico. Por exemplo, é reiteradamente propagada [sic] nos meios de comunicação, em documentos oficiais e oficiosos, a falta de competitividade do Brasil no mercado concorrencial internacional; a solução para tal problema encontra-se, em parte, pela elevação da qualidade da educação. Analisemos mais de perto estes dois termos chaves - competitividade e qualidade - termos estes impregnados nas políticas educacionais. Por competitividade entende-se a capacidade de competir em algum grau de vantagem, de conseguir inserir no mercado determinadas mercadorias com preço abaixo do seu valor social médio. A realização dos objetivos propostos com vistas a alcançar a competitividade oculta sob uma fachada simplificada o sociometabolismo da barbárie.

Assim, naquilo que será exposto e problematizado neste artigo, entendemos ser de suma importância apresentar os projetos educativos em disputa no que se referem ao Ensino Médio, disputas estas que encerram reorganizações curriculares e padronizações formativas, retirando dos professores, sobretudo, a proposição de práticas educativas que possam colocar em xeque os valores do mercado ou a ideologia da lógica do capital. Em tempos de 'escolas sem partido'4 e avanços preocupantes do ideário fascista em

\footnotetext{
${ }^{4}$ Segundo Daniel Ferraz Chiozzini, professor da PUC/SP, "desde a aprovação do afastamento da presidenta Dilma Rousseff, o governo interino vem anunciando medidas que podem retirar importantes conquistas da sociedade brasileira no âmbito da Educação. Entre elas está o fim do percentual mínimo de investimentos de estados e municípios garantidos pela Constituição Federal de 1988 [...]. Os recentes projetos de lei capitaneados pelo movimento intitulado Escola Sem Partido, em discussão no âmbito do Poder Legislativo da União, estados e municípios, são a face mais retrógrada dessas mudanças. A justificativa apresentada é combater uma suposta 'doutrinação de esquerda', evocando a precedência aos valores de ordem familiar sobre a educação escolar nos aspectos relacionados à educação moral, sexual e religiosa", conforme descreve o PL 7180/2014. Um dos projetos de lei em questão (PL 1411/2015), embora não diretamente apoiado pelo dito movimento, tipifica o crime de assédio ideológico, permitindo a prisão de qualquer indivíduo que 'condicione o aluno a adotar determinado posicionamento político, partidário, ideológico ou qualquer tipo de constrangimento causado por outrem ao aluno por adotar posicionamento diverso do seu, independente de quem seja o agente'. É preciso ficar bem claro: 1) Não existe oposição entre escola e família no processo educativo. Os documentos e leis que regem a nossa educação reconhecem que ambas interferem no processo de formação do indivíduo, mas a escola brasileira atual não tem o poder de doutrinar indivíduos, ainda que os autores desses projetos a ela atribuam essa função. Nossos problemas educacionais são de outra ordem; 2) Os projetos criam mecanismos
} 
várias instâncias da vida pública, parece-nos mais do que necessária a participação política dos professores e estudantes da Educação Básica (com destaque para o Ensino Médio) naquilo que atingirá a sua identidade profissional e o seu processo formativo, respectivamente.

\section{Currículo, avaliação, gestão e formação docente}

Antes de tratarmos sobre o currículo, a avaliação, a gestão e a formação de professores, entendemos ser importante apresentar, ainda que brevemente, os interlocutores escolhidos pela Folha de S. Paulo para tratar da temática em tela.

A estudante Bárbara Melo foi eleita, aos 19 anos, como presidente da UBES (União Brasileira dos Estudantes) e sempre teve atuação intensa nos grêmios estudantis durante a sua Educação Básica. Cursou Administração em nível técnico e fez estágio na Eletrobrás; também foi presidente da AMES (Associação Municipal dos Estudantes do Rio de Janeiro) e, na condição de presidente da AMES, foi uma das idealizadoras do Fórum de Lutas contra o Aumento da passagem no Rio de Janeiro (REDE UBES, 2016).

Daniel Cara, por seu turno, é coordenador geral da Campanha Nacional pelo Direito à Educação, desde 2006. É Bacharel em Ciências Sociais e Mestre em Ciências Políticas pela USP. Participou das comissões organizadoras da CONEB (Conferência Nacional da Educação Básica) entre 2007 e 2008 (CENTRO DE REFERÊNCIAS EM EDUCAÇÃO INTEGRAL, 2016). Já Herman Voorwald foi secretário de Educação do governo Alckmin em São Paulo. Teve de deixar o cargo após as ocupações das escolas de São Paulo pelos estudantes, depois de uma mal fadada política de reorientação curricular, que não foi devidamente discutida com as comunidades escolares. Foi reitor da Universidade

\footnotetext{
policialescos que podem, na prática, ser utilizados para coibir o professor ou aluno que debata um noticiário político, questões de gênero ou sexualidade ou trabalhe com a teoria de evolução das espécies, por exemplo. Assim, engessam e oprimem especialmente a escola pública brasileira, já tão precarizada. Utilizando o argumento falacioso da defesa dos Direitos Humanos e um compromisso com a pluralidade de ideias, tais projetos de lei criam instrumentos de controle da educação escolar em suas diversas instâncias como avaliação, materiais didáticos, formação de professores, entre outros, superando inclusive aqueles criados durante períodos ditatoriais em nosso país. Daí a importância de serem veementemente repudiados por todos que defendem uma educação efetivamente democrática (CHIOZZINI, 2016).
} 
Estadual Paulista (UNESP) e é formado em Engenharia Mecânica pela mesma universidade (NOVO, 2016).

Ocimar Alavarse estudou Engenharia Eletrônica na Escola de Engenharia de São Carlos na USP; Licenciado em Pedagogia pela Universidade Federal de São Carlos, Mestre e Doutor em Educação pela USP (OCIMAR, 2016). É um dos autores dos cadernos formativos do Pacto Nacional pelo Fortalecimento do Ensino Médio (PNEM). Priscila Cruz é fundadora e Presidente-Executiva do Movimento Todos pela Educação. Graduada em Administração pela Fundação Getúlio Vargas e em Direito pela USP (ARTICULAÇÃO PÚBLICO-PRIVADA PELA BASE NACIONAL COMUM CURRICULAR, 2016). Rafael Luchesi é membro titular do Fórum Nacional de Educação (FNE) representando as confederações dos empresários e do Sistema "S". Sua experiência reside na área econômica, com ênfase em inovação tecnológica (FÓRUM NACIONAL DE EDUCAÇÃO, 2016).

Ricardo Henriques é superintendente executivo do Instituto Unibanco e Professor no Departamento de Economia da Universidade Federal Fluminense. Foi secretário nacional de Educação Continuada, Alfabetização e Diversidade (SECAD) do MEC entre 2004 e 2007 (INSTITUTO UNIBANCO, 2016). Roberto Leão é professor da rede pública de São Paulo. Graduado em Pedagogia e Educação Artística, com especialização em gestão escolar. Foi vice-presidente do Sindicato dos Professores do Ensino Oficial do Estado de São Paulo (APEOESP). Atualmente é membro da Direção Nacional da CUT (BOLETIM DO CNTE, 2016). Rossieli Soares da Silva é o atual Secretário de Educação do Amazonas (PORTAL DO ZACARIAS, 2016). Sólon Caldas é Mestre em Gestão do Conhecimento e Tecnologia da Informação pela Universidade Católica de Brasília, MBA em Gestão Empresarial e Bacharel em Administração. Atualmente ocupa o cargo de Diretor Executivo na Associação Brasileira de Mantenedoras de Ensino Superior - ABMES e Professor Universitário (SÓLON, 2016).

Sylvia Gouvea é sócio-fundadora da Escola Lourenço Castanho e membro do Conselho Estadual de Educação de São Paulo (REDE BRASIL ATUAL, 2016). E, por fim, Wagner Santos, sociólogo e coordenador do programa “jovens urbanos”, uma iniciativa da Fundação Itaú Social, que tem a coordenação técnica do Centro de Estudos e Pesquisas em Educação, Cultura e Ação Comunitária (SANTOS, 2016). 
Levando-se em consideração o desequilíbrio de opiniões ou de perspectivas teóricas/formativas no conjunto de 'interlocutores' ou de 'especialistas' convidados pela Folha de S. Paulo, ficam explicitadas as justificativas encontradas para celebrar um modelo de gestão escolar assentado no 'gerencialismo do setor público' ou um modelo de gestão empresarial na escola pública acalcanhada na 'responsabilização pelos resultados'. Não por acaso e de maneira reiterada, os editoriais da Folha de S. Paulo, quando tratam do fenômeno educacional, reproduzem como um mantra a ideia de que o fundo público destinado às escolas e também às universidades seja gerenciado por Organizações Sociais (OS):

No apagar das luzes de 2015 o jornal Folha de S. Paulo em seu editorial de 27 de dezembro, retomou a discussão sobre os rumos da educação pública no Brasil, por meio de 'cinco ideias para debate'. [...] a Folha de S. Paulo está preocupada com aspectos relacionados à gestão do fundo público para a Educação Básica e o Ensino Superior. O editorial chega a mencionar a necessidade de um 'choque de gestão' nas escolas públicas, baseando-se, para tanto, em referências teóricas de experts do universo privado. Logo, a Folha de S. Paulo se acalcanha em cinco objetivos para aprimorar a gestão das escolas públicas e 'premiar' por meio de bônus de desempenho os/as professores/as: 1) enfatizar o gasto com o ensino básico, e não com o universitário; 2) garantir seis horas efetivas de aula por dia (hoje são duas); 3) pôr ênfase em português e matemática no currículo nacional; 4) dar autonomia a mestres e diretores e facilitar a demissão dos piores; 5) fechar escolas ruins ou entregar a sua gestão a organizações sociais (OS). No que tange à primeira ideia, entendemos que o financiamento da educação pública precisa se dar em todos os níveis e modalidades de ensino, sem qualquer distinção. O que está em jogo aqui é a defesa desta empresa de comunicação com o pagamento de mensalidades nas universidades estatais, o que pode levar ao definitivo desfecho do caráter público das instituições de ensino superior mantidas pela sociedade brasileira. A terceira ideia, por seu turno, leva em consideração um currículo escolar cada vez mais restrito, como se as demais áreas do conhecimento fossem meros apêndices, além de a mesma estar coadunada com a perspectiva duvidosa das avaliações internacionais em larga escala (lógica dos ranqueamentos). Em síntese, se o fundo público para o setor educacional fosse, de fato, prioridade de Estado, a perspectiva privatista não teria ganhado tanto terreno nestas últimas duas décadas, especialmente com a reforma neoliberal iniciada na década de 1990. Para a Folha de S. Paulo a não entrega do fundo público para as organizações sociais representa tão somente 'preconceito ideológico' e não a terceirização deliberada da administração pública para o setor empresarial. Estamos, de fato, diante 
de projetos educacionais em disputa, e o caráter público da Educação Básica e do Ensino Superior correm riscos cada vez mais iminentes de serem extintos sob o manto da racionalidade meritocrática! (DANTAS, 2016, p. 33-34)

Destarte, o controle do trabalho docente na Educação Básica passa a se dar por meio de avaliações em larga escala ${ }^{5}$ e por um estreitamento curricular de reduzido espectro formativo, notadamente para as crianças e jovens pertencentes à classe trabalhadora (SANTOS, 2014, p. 99-100). A reforma educativa sob a égide gerencialista em nosso país vem desde a década de 1990, levada a cabo de forma mais aguda durante o governo FHC (1995-2002) e com permanências funestas durante o governo Lula (20032010). Nos termos de Evangelista (2014, p. 139),

\begin{abstract}
Ressalta-se, ademais, que FHC afirmava que a 'ação estatal' devia ser substituída pela 'ação pública', estimulando a parceria público-privada e criando o solo no qual cresceria desmedidamente, no governo Lula, aparelhos privados de hegemonia, de todos os tipos, arautos dos interesses burgueses. Um exemplo cristalino desse processo é o 'Todos pela Educação', criado em 2006, que se jacta de ter entre seus parceiros Gerdau, Santander, Bradesco, entre outros. A 'sociedade civil', ressignificada, tornou-se 'locus' de responsabilização social para a solução de problemas econômicos.
\end{abstract}

Assim, não é possível descolarmos as questões que envolvem a avaliação escolar, em todos os seus níveis e modalidades de ensino, de seu desenho ou reorientação curricular. Isto significa que os processos avaliativos, especialmente na Educação Básica, estão atravessados por dimensões políticas, culturais, ideológicas e econômicas. Há algum tempo, o educador estadunidense Michael Apple (1942-) tem desenvolvido importantes e profícuas discussões referentes à reorientação curricular nos EUA, que

\footnotetext{
5 Para Zanardini (2014, p. 75), os processos avaliativos correspondem a pressupostos ontológicos, resultados do trabalho humano, portanto, constitutivos do ser social: "São caracterizações de intencionalidades distintas, partem de projetos sociais distintos, têm em vista modelos de homens distintos, pois a avaliação consubstanciada no trabalho carrega em si uma positividade que necessariamente resulta numa mudança qualitativa na práxis social, impulsionando os homens à frente, ao passo que a avaliação levada a cabo pelas classes dominantes, diretamente ligadas à manutenção da sociabilidade baseada na desigualdade, intenta a conservação da dominação do homem pelo homem, por mais que entre seus argumentos ideológicos, propague um ajuste social via educação".
} 
podem facilmente se associar ao que vem ocorrendo em nosso país, em tempos de debate da Base Nacional Comum Curricular (BNCC). Apple identifica em um de seus estudos determinadas alianças sociais e econômicas que estariam ameaçando situações de igualdade nos territórios educativos, escamoteadas sob o verniz do 'discurso da melhoria da competitividade' e do aumento dos postos de trabalho. Tais alianças de classe se configuram em quatro grandes 'facções', conforme termos de Apple: 1) neoliberais; 2) neoconservadores; 3) populistas autoritários e 4) classe média profissional (APPLE, 2002, p. 57).

Para o primeiro grupo (neoliberais), as escolas públicas são vistas como 'buracos negros', sem resultados adequados; os estudantes são encarados como capital humano, em que qualquer investimento que não seja o estritamente econômico é compreendido como ‘suspeito'. Em outras palavras, as tomadas de decisão (numa sociedade bastante estratificada), aparentam dar a todos iguais oportunidades de escolarização, todavia, transformando as responsabilidades das tomadas de decisão da esfera pública para a esfera privada, reduzindo a ação coletiva e/ou popular que garanta, efetivamente, a qualidade de educação para todos. Os neoliberais do campo da educação têm uma 'fé essencial na lealdade e justiça dos mercados'; porém, estas estratégias economicistas e despolitizadoras acabam por elevar as crescentes desigualdades de recursos e poder (APPLE, 2002, p. 57-64).

Já os neoconservadores entendem que não é o mercado que resolverá os problemas do currículo escolar, mas um Estado interventor que garantirá apenas os conteúdos e métodos 'legítimos' a serem ensinados e utilizados. Em síntese, incorre-se na ideia de um currículo único, que defenda os valores tradicionais (dos imigrantes brancos) e sem o reconhecimento da luta de classes. E o mais grave: a defesa de um determinismo genético ou racial na capacidade de aprendizagem dos/as estudantes (APPLE, 2002, p. 6570). Coadunado a este pensamento reacionário, o populismo autoritário, assentado na direita cristã, entende que as questões de gênero e a ideia de família são unidades divinas e orgânicas, que resolvem por si só, sem mediações históricas, o 'egoísmo masculino' e o 'altruísmo feminino' (APPLE, 2002, p. 70-73). Por fim, a chamada 'classe média profissional' (ideologicamente contraditória, segundo Apple), por meio da defesa das 
charter schools, ou seja, escolas públicas mantidas por meio de gerenciamento privado, preocupadas tão somente com os resultados acadêmicos nas disciplinas tradicionais e no ensino prático tradicional, são muito suscetíveis a uma ordem discursiva aparentemente includente, mas que oculta opressões, preconceitos e estereótipos (APPLE, 2002, p. 7374). Coincidência ou não vivemos dilemas semelhantes no Brasil, haja vista as (in)tensas discussões relacionadas ao Plano Nacional de Educação (PNE), à BNCC, e também à excrescência denominada “Escola sem Partido".

Por meio do Decreto 6.074/2007, durante o governo Lula (2003-2010), implantouse em todo o país o IDEB (Índice de Desenvolvimento da Educação Básica), referente ao Plano de Metas Compromisso Todos pela Educação. O IDEB, como se sabe, cruza os resultados de desempenho nas provas do SAEB com as taxas de aprovação de cada uma das unidades escolares e redes de ensino, sendo de responsabilidade do INEP (Instituto Nacional de Estudos e Pesquisas Educacionais Anísio Teixeira) a divulgação destes resultados. Todavia, se por um lado, temos concordância de que a avaliação do trabalho pedagógico é fundamental para que possamos compreender os resultados dos itinerários formativos dos estudantes (e aqui me refiro, especialmente, ao Ensino Médio), por outro lado, temos de compreender que as avaliações externas em larga escala submetem os professores a uma imensa pressão, retirando-lhes a autonomia profissional e impedindoIhes de desenvolver um trabalho pedagógico consistente e consequente do ponto de vista conceitual, político e humano. Estas políticas públicas de responsabilização (accountability) acabam por favorecer, ao fim e ao cabo, a lógica meritocrática e a culpabilização dos professores, ferindo preceitos democráticos. Acirra-se, deste modo, uma competição entre as escolas e um processo de ranqueamento que empobrece o conjunto das atividades pedagógicas desenvolvidas nestes territórios educativos.

Nessa perspectiva, segundo Sousa (2003, p. 181), os conteúdos a serem ensinados na escola são os mesmos que serão 'cobrados' pelas avaliações em larga escala, atribuindo ao potencial do/a estudante o seu "sucesso pessoal e profissional, abstraindo os fatores econômicos e sociais" (SOUSA, 2003, p. 182). Em outras palavras, 
As políticas educacionais ao contemplarem em sua formulação e realização a comparação, a classificação e a seleção incorporam, consequentemente, como inerentes aos seus resultados a exclusão, 0 que é incompatível com o direito de todos à educação. (SOUSA, 2003, p. 188)

Já Fernandes pondera que as escolas públicas passaram a ser exigidas a partir de uma 'lógica empresarial', na qual os resultados são mais importantes que o processo de ensino e aprendizagem:

Podemos dizer que chegamos à educação do treino e do produto. Todos os meios justificariam os fins: obter um alto Índice de Desenvolvimento da Educação Básica (IDEB). A promessa é de que isso nos colocará no topo e conquistaremos uma educação de qualidade [...]. Para as políticas que se baseiam nos exames de larga escala, os processos importam muito pouco. A avaliação é vista como possibilidade de medição de um conhecimento que, por sua vez, pode ser medido, destituído de qualquer complexidade e subjetividade. Importa um currículo enxuto, um bom treinamento, um 'professor tarefeiro' e um 'aluno marca $\mathrm{x}$ '. (FERNANDES, 2015, p. 402)

Este tipo de avaliação, baseada no mero treinamento, ocasiona, por seu turno, uma simplificação da dimensão curricular. A cultura neoliberal, como nos aponta Apple (2002), possui esta capacidade de se imiscuir no senso comum, por meio de valores questionáveis e terminologias (qualidade, por exemplo), que mais ocultam do que esclarecem: “Os resultados demonstram que o conceito de qualidade, polissêmico e construído sócio-historicamente, é utilizado de forma indiscriminada nos documentos analisados e que a avaliação externa aparece como redentora dos males da educação" (FERNANDES, 2015, p. 405).

As políticas públicas educacionais em vigor no Brasil não poderiam ser mais trágicas e devastadoras para os trabalhadores em educação, tendo em vista que desqualificam e marginalizam os/as profissionais do magistério naquilo que Ihes é inerente, ou seja, ensinar! As avaliações externas em larga escala estão reduzindo os territórios educativos a meras simplificações de conteúdos pré-selecionados, condizentes 
com a perspectiva do capital, que continua necessitando de trabalhadores ordeiros, despolitizados e alienados!

A avaliação escolar adotada por estas políticas públicas vem acompanhada de outras estratégias 'formativas', ou melhor, de treinamentos específicos, sintetizados em manuais didáticos instrucionais e comercializados em larga esfera por grupos ou sistemas de ensino privados. De fato, deveríamos nos perguntar também o que são 'políticas' e o que são 'programas' educacionais, já que a descontinuidade dos programas educativos, notadamente na Educação Básica, revela o quanto o Estado Neoliberal desconsidera a Educação como área de investimento estratégico.

Causa-nos surpresa, contudo, que o evento promovido pela Folha de S. Paulo e o Instituto Unibanco tenham desprezado olimpicamente o Pacto Nacional pelo Fortalecimento do Ensino Médio (PNEM), instituído por meio da Portaria Ministerial $\mathrm{n}^{\circ}$ 1.140, de 22 de novembro de 2013, contemplando dentre várias ações, a formação continuada docente e dos coordenadores pedagógicos do Ensino Médio, de forma colaborativa entre MEC, Secretarias Estaduais de Educação e universidades. Tal ação teria como objetivo ainda discutir a formação continuada docente à luz das novas Diretrizes Curriculares Nacionais para o Ensino Médio (DCNEM), por meio da Resolução CNE/CEB nº 2, de janeiro de 2012. A formação docente se articularia ao redesenho curricular em desenvolvimento nas escolas públicas de Ensino Médio a partir destas Diretrizes (MEC, 2013). Isto denota que há, sem dúvida, 'projetos em disputa' nesta etapa da Educação Básica, e que está em curso um processo formativo de 'novo tipo' ${ }^{6}$ para a juventude brasileira, conforme análise realizada por Nogara Junior (2015).

\section{Considerações Finais}

No momento em que elaborávamos este texto, a presidente Dilma Rousseff foi afastada da presidência da República, com desdobramentos que se fizeram sentir imediatamente com o novo governo que se instituiu. No que tange especialmente ao

\footnotetext{
${ }^{6}$ Em outras palavras, uma formação no Ensino Médio cada vez mais simplificada para os filhos da classe trabalhadora, objetivando o exercício ou as funções no mundo de trabalho que exijam apenas 'trabalho simples' (MARTINS; NEVES, 2015).
} 
Ensino Médio, foi emitida pelo governo federal a Medida Provisória (MP) 746/20167, que modifica o currículo e a carga horária desta etapa da Educação Básica, sem qualquer diálogo com as instituições de ensino, associações educacionais e/ou grupos de pesquisa das universidades públicas. Além disso, a Proposta de Emenda Constitucional (PEC) $\mathrm{n}^{\circ}$ 241/16, que congela os gastos públicos no país por vinte anos, com reajustes apenas pelo Índice Nacional de Preços ao Consumidor Amplo (IPCA), afetará, sobremaneira, os investimentos na esfera educacional. Tal emenda foi aprovada pela Câmara dos Deputados e pelo Senado.

As mudanças na natureza da Educação Básica no Brasil, tendo como marco fundacional a década de 1990 até os dias atuais, vêm sendo problematizadas de forma aguda por diversos grupos de pesquisa, que assinalam o quanto os organismos internacionais multilaterais vêm definindo as concepções ou modelos formativos na Educação Básica dos países periféricos do capital (MARTINS; NEVES, 2015).

Nesta direção, os desafios para a classe docente e para a Educação nacional neste momento são gigantescos! São várias as frentes de luta com decorrências futuras complexas, especialmente no campo do currículo da Educação Básica. As mobilizações sociais tendem a crescer no país. Por outro lado, entendemos que maniqueísmos e simplificações analíticas sobre o que ocasionou o afastamento da presidente Dilma Rousseff, não contribuem para este debate e para o devido avanço em relação às proposições políticas e pedagógicas ocorridas nas duas últimas décadas no Brasil. Há a necessidade de defendermos a frágil democracia brasileira, mas mirando um horizonte em que a educação pública se configure como área efetiva de investimento estratégico, preferencialmente para aqueles e aquelas que mais necessitam de uma escola pública, laica e socialmente referendada.

\footnotetext{
${ }^{7}$ Sancionada pela presidência da República já tem força de Lei (Lei 13.415/17) desde fevereiro de 2017.
} 


\section{Referências}

APPLE, Michael. "Endireitar" a educação: as escolas e a nova aliança conservadora.

Currículo sem fronteiras, v. 3, n. 1, p. 50-59, jan./jun. 2002.

ARTICULAÇÃO público-privada pela base nacional comum curricular. Disponível em: < http://congressogife.org.br/2016/palestra/parcerias-com-governos-na-educacao/>. Acesso em: 31 mai. 2016.

BOLETIM DO CNTE. Brasília, 19 jan. 2014. Disponível em: <http://www.cnte.org.br/images/stories/2014/32_congresso_nacional_boletim_dia_19_we b_final3.pdf.>. Acesso em: 31 mai. 2016.

BRASIL. Ministério da educação. Gabinete do ministro. Portaria $\mathbf{n}^{\circ}$ 1.140, de 22 de novembro de 2013. Brasília: MEC, 2013.

CENTRO DE REFERÊNCIAS EM EDUCAÇÃO INTEGRAL. Daniel Cara. 10/07/2014. Disponível em: http://educacaointegral.org.br/especialistas/daniel-cara/. Acesso em: 31 mai. 2016.

CHIOZZINI, Daniel Ferraz. A falácia do escola sem partido. Disponível em: http://educacaointegral.org.br/noticias/falacia-escola-sem-partido/. Acesso em: 02 jun. 2016.

DANTAS, Jéferson. Competências e habilidades e a formação docente no contexto das Leis 5.692/1971 e 9.394/1996 em Santa Catarina. Rio de Janeiro: CBJE, 2009.

DANTAS, Jéferson. Da ditadura militar ao Estado Neoliberal: a organização escolar brasileira e a formação docente em Santa Catarina. Rio de Janeiro: CBJE, 2014.

DANTAS, Jéferson. A perspectiva da Folha de S. Paulo sobre a educação pública. In: DANTAS, Jéferson. Construir espaços coletivos de esperança em tempos de discurso de ódio. Florianópolis: Insular, 2016, p. 33-34.

EVANGELISTA, Olinda. Políticas públicas educacionais contemporâneas, formação docente e impactos na escola. In: SANTOS, Alex Sandro Batista dos; EVANGELISTA, Olinda (Orgs.). Políticas para a educação básica no Brasil. Florianópolis: UFSC/CED/NUP, 2014, p. 137-151. 
FERNANDES, Cláudia de Oliveira. Avaliação, currículo e suas implicações: projetos de sociedade em disputa. Revista Retratos da Escola, Brasília, v.9, n. 17, p. 397-408, jul.dez/2015.

FERREIRA, Windyz Brazão. O conceito de diversidade no BNCC - Relações de poder e interesses ocultos. Revista Retratos da Escola, Brasília, v.9, n. 17, p. 299-319, jul.dez/2015.

FÓRUM NACIONAL DE EDUCAÇÃO. Brasília: MEC, 2016. Disponível em: < http://fne.mec.gov.br/93-uncategorised/minicurriculo/453-rafael-esmeraldo-lucchesiramacciotti. >. Acesso em: 31 maio. 2016.

GERALDI, João Wanderley. O ensino de língua portuguesa e a Base Nacional Comum Curricular, Revista Retratos da Escola, Brasília, v.9, n. 17, p. 381-396, jul.dez/2015.

INSTITUTO UNIBANCO. [Site]. Rio de Janeiro, 2016. Disponível em: < http://www.institutounibanco.org.br/membros-governanca/ricardo-henriques.>. Acesso em 31 mai. 2016.

MARTINS, André Silva; NEVES, Lúcia Maria Wanderley (Orgs.). Educação básica: tragédia anunciada? São Paulo: Xamã, 2015.

NOGARA JUNIOR, Gilberto. O programa ensino médio inovador (PROEMI) no contexto das políticas do Banco Mundial (BM): rumo à formação de trabalhadores de novo tipo. 2015. Dissertação (Mestrado em Educação) - Universidade Federal de Santa Catarina, Centro de Ciências da Educação, Programa de Pós-Graduação em Educação, Florianópolis, 2015.

NOVO secretário da Educação de SP, Herman Voorwald é reitor da Unesp desde 2009. UOL Educação. São Paulo, 17 dez.2012. Disponível em: < http://educacao.uol.com.br/noticias/2010/12/17/novo-secretario-da-educacao-de-spherman-voorwald-e-reitor-da-unesp-desde-2009.htm.>. Acesso em: 31 mai. 2016.

O NÓ do ensino médio: como melhorar a educação pública no país. Folha de S. Paulo, São Paulo, p. 1, 5 set. 2015.

OCIMAR Munhoz Alavarse. In: USP Digital. São Paulo, 2016. Disponível em: <https://uspdigital.usp.br/tycho/CurriculoLattesMostrar?codpub=27A1E3FF3C62\#Areasdea tuacao.>. Acesso em: 31 maio 2016.

PORTAL DO ZACARIAS. Amazonas, 2016. Disponível em: < http://portaldozacarias.com.br/site/noticia/Secretario-da-Seduc-Amazonas-RossieliSoares-e-eleito-vice-presidente-do-Consed/.>. Acesso em: 31 mai. 2016. 
REDE BRASIL ATUAL. Educação. Disponível em: < http://www.redebrasilatual.com.br/educacao/2013/og/estudantes-e-pais-querem-espacoem-conselho-estadual-dominado-por-empresarios-da-educacao-9075.html.>. Acesso em: 31 mai. 2016.

REDE UBES. [Site], São Paulo, 2016. Disponível em: < http://ubes.org.br/2013/cariocabarbara-melo-e-eleita-presidenta-da-uniao-brasileira-dos-estudantes-secundaristasubes/.>. Acesso em: 8 abr.. 2016.

SANTOS, Marcia Luzia. Gestão por resultados e a intensificação do trabalho dos professores da Rede Municipal de Florianópolis. In: SANTOS, Alex Sandro Batista dos; EVANGELISTA, Olinda (Orgs.). Políticas para a educação básica no Brasil. Florianópolis: UFSC/CED/NUP, 2014, p. 95-114.

SANTOS, Wagner Antonio. [Entrevista concedida ao Portal do ESPRO]. São Paulo, 2016. . Disponível em: <http://www.espro.org.br/noticias/77-boletim-espro-na-sua-empresa/108718out-entrevista-wagner-antonio-santos.>. Acesso em 31 maio 2016.

SÓLON Hormidas Caldas. In: Escavador, 2016. Disponível em: <http://www.escavador.com/sobre/2675536/solon-hormidas-caldas\#atuacaoprofissional.>. Acesso em 31 mai. 2016.

SOUSA, Sandra Maria. Zákia Lian. Possíveis impactos das políticas de avaliação no currículo escolar. Cadernos de Pesquisa, n. 119, p. 175-190, jul. 2003.

ZANARDINI, João Batista. Políticas de avaliação da educação pública. In: SANTOS, Alex Sandro Batista dos; EVANGELISTA, Olinda (Orgs.). Políticas para a educação básica no Brasil. Florianópolis: UFSC/CED/NUP, 2014, p. 67-93. 